\title{
Sexual satisfaction and self-esteem in women with primary infertility
}

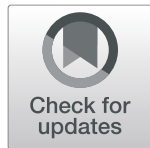

\author{
Abdelhady Abdelhady Zayed ${ }^{1 *}$ and Mohamed Adel El-Hadidy ${ }^{2}$
}

\begin{abstract}
Background: Infertility may adversely affect sexual satisfaction and self-esteem of the infertile couples.

Main body: This study aims to assess self-esteem (sexual and general), anxiety, and depression in women with primary infertility. It is a comparative cross-sectional study and data collection covers a 1-year period. The study population consisted of 284 women, of whom 150, who attended the gynecology outpatient clinic of the hospital for contraception in the control group, and 134, who attended the gynecology department asking for treatment from primary infertility in the study group. All participants were examined using Mini-International Neuropsychiatric Interview (MINI), Wechsler Adult Intelligence Scale-Revised (WAIS-R), Hamilton Anxiety Scale ( HAM-A), Hamilton Depression scales, socioeconomic standard using The Egyptian Classification of Socioeconomic Standard by El Gilany 2002, self-esteem using the Arabic translation of Rosenberg Self-esteem Scale, and Self-esteem and Relationship questionnaire (SEAR).

In the present study, women with primary infertility showed a higher prevalence of depression and anxiety with a statistically significant difference from fertile women. In addition, women with primary infertility showed lower general self-esteem, sexual satisfaction, sexual relationship, and sexual self-esteem than women with children and the difference was statistically significant.
\end{abstract}

Conclusion: Infertility has a negative effect on women's self-esteem, sexual activity, and psychological function.

Keywords: Infertility, Self-esteem, Sexual satisfaction, Depression, Anxiety

\section{Background}

Reduced sex drive can have a profound effect on the individual's quality of life and other aspects of selffunctioning [1]. Women's lack of confidence or negative body images may affect their sexual life [1]. WHO (2013) defines infertility as a disease of the reproductive system and results in the failure to achieve a clinical pregnancy after 12 months or more of regular unprotected sexual intercourse (and there is no other reason, such as breast-feeding or postpartum amenorrhea) [2]. Primary infertility is infertility in a couple who have never had a child. Secondary infertility is the failure to conceive following a previous pregnancy. Infertility leads

\footnotetext{
*Correspondence: zayed_hady@yahoo.com

${ }^{1}$ Gynecological and Obstetric Department, Mansoura Faculty of Medicine, Mansoura University, Mansoura, Egypt

Full list of author information is available at the end of the article
}

to negative consequences in most marital lives [3], especially the wife's self-esteem and the concept of her body image [4]. Infertility can also badly affect the couple's sexual life [5]. Most wives show a marked decrease in frequency, quality, and satisfaction of their sexual life including performance and practice after being diagnosed with infertility [6]. On the other hand, husbands showed less effect than their wives. Other studies found that erectile dysfunction and premature ejaculation are more prevalent in husbands with infertility than men with children [7]. A recent meta-analysis of 14 studies concluded that husbands have an increased rate of erectile dysfunction, while wives with primary infertility complain of decreased libido [8]. In general, many studies found that overall sexual relation and couple's life could be badly affected by infertility [9].

\section{Springer Open}

(ㅇ The Author(s). 2020 Open Access This article is licensed under a Creative Commons Attribution 4.0 International License, which permits use, sharing, adaptation, distribution and reproduction in any medium or format, as long as you give appropriate credit to the original author(s) and the source, provide a link to the Creative Commons licence, and indicate if changes were made. The images or other third party material in this article are included in the article's Creative Commons licence, unless indicated otherwise in a credit line to the material. If material is not included in the article's Creative Commons licence and your intended use is not permitted by statutory regulation or exceeds the permitted use, you will need to obtain permission directly from the copyright holder. To view a copy of this licence, visit http://creativecommons.org/licenses/by/4.0/. 
Women who discover that they are infertile usually appear normal but they experience distress. They find it difficult to express their feelings and they have to suppress feelings of grief, depression, anxiety, anger, frustration, as well as the loss of self-esteem, self-confidence, and a sense of control over their destiny.

The hypothesis of this study was that women with primary infertility have low general and sexual self-esteem. They also have a high prevalence of depression and anxiety. Self-esteem is one of the important aspects of personality and determinants of human behavioral characteristics and development. Self-esteem is a set of attitudes and beliefs expressed by persons in their relationships with the outside world. Self-esteem indicates the degree to which a person perceives him/herself as able, valuable, and important [10]. General self-esteem used to describe a person's overall sense of self-worth or personal value. In other words, how much you appreciate and like yourself. Sexual self-esteem defined as how you view your sense of self as a sexual being [11]. Low self-esteem can lead to many physical and mental disorders such as anxiety, depression, behavioral, and communication problems [10]. Sexuality is among the important needs of life. To be a sexually satisfied person should have good sexual self-esteem. Sexual disorder is difficulty experienced by an individual or a couple during any stage of normal sexual activity (physical pleasure, desire, preference, arousal or orgasm) [12]. Sexual dysfunction disorders classified into 4 categories: sexual desire disorders, arousal disorders, orgasm disorders, and pain disorders [13]. Infertility can affect a person's sexual esteem and also can lead to sexual dysfunction. The prevalence of sexual disorders in infertile couples remains unclear [14]. The aim of this study was to assess self-esteem (sexual and general), anxiety, and depression in women with primary infertility.

\section{Main text}

\section{Patients and methods}

This cross-sectional comparative study was carried out in the outpatient clinic of Obstetrics and Gynecology Department, Mansoura University, during the period from 1st of September 2016 to 31st of August 2017. It was carried out at the obstetrics and gynecology outpatient clinic. In the study, a total of 201 women who attended the clinic for treatment from primary infertility were diagnosed with infertility as they were unable to conceive after regular unprotected sex in a marital relationship for 1 year [2]. All women were examined by a gynecologist and were invited to take part in this study. Sixty-four patients were excluded as they or their husbands refused to give consent to share in this study. The remaining patients were referred to a psychiatrist. Three patients dropped out at the time of the referral or the psychiatric assessment. The rest of the patients were interviewed using the MiniInternational Neuropsychiatric Interview (MINI) version 5. The scale had been previously translated and validated into Arabic [15]. All patients were diagnosed using DSM5 criteria for any psychiatric disorders [16].

The control group is composed of 150 volunteers who attended the gynecology outpatient clinic for contraception and reported that they were married and have a number of children. They were healthy with no medical or psychiatric disorders.

One hundred thirty-four women were diagnosed with infertility on grounds of failure to conceive after 1 year of unprotected sex in a marital relationship [2]. A specially designed sheet was used to collect the needed information. It includes age, education, residence, socioeconomic standard, religious background, marriage, and sex information.

All patients underwent a full clinical examination including general, abdominal, and local gynecologic

Table 1 Socio-demographic data in both groups

\begin{tabular}{|c|c|c|c|c|c|c|}
\hline & & \multicolumn{2}{|l|}{ Case/control } & \multirow[t]{2}{*}{ Total } & \multirow{2}{*}{$\begin{array}{l}\text { Chi- } \\
\text { square }\end{array}$} & \multirow[t]{2}{*}{ Sig } \\
\hline & & Control & Case & & & \\
\hline \multirow[t]{2}{*}{ Residence } & Rural & $114(76.0 \%)$ & $103(76.9 \%)$ & $21776.4 \%$ & 0.029 & 0.864 \\
\hline & Urban & $36(24.0 \%)$ & $31(23.1 \%)$ & $67(23.6 \%)$ & & \\
\hline \multirow[t]{4}{*}{ Socio-economic standard } & Low & $39(26.0 \%)$ & $26(19.4 \%)$ & $65(22.9 \%)$ & 2.535 & 0.283 \\
\hline & Very low & $99(66.0 \%)$ & $92(68.7 \%)$ & $191(67.3 \%)$ & & \\
\hline & Middle & $12(8.0 \%)$ & $16(11.9 \%)$ & $28(9.9 \%)$ & & \\
\hline & High & $0(0.0)$ & $0(0.0)$ & $0(0.0)$ & & \\
\hline \multirow[t]{2}{*}{ Religion } & Christian & $13(8.7 \%)$ & $10(7.5 \%)$ & $23(8.1 \%)$ & 0.138 & 0.829 \\
\hline & Moslem & $137(91.3 \%)$ & $124(92.5 \%)$ & $261(91.9 \%)$ & & \\
\hline \multirow[t]{2}{*}{ Type of marriage } & Arranged & $98(65.3 \%)$ & $85(63.4 \%)$ & $183(64.4 \%)$ & 0.112 & 0.417 \\
\hline & Love & $52(34.7 \%)$ & $49(36.6 \%)$ & $101(35.6 \%)$ & & \\
\hline Total & & $150(100 \%)$ & $134(100 \%)$ & $284(100 \%)$ & & \\
\hline
\end{tabular}

Data presented as chi-square, $p<0.05$ is considered significant 
Table 2 Age, IQ, and duration of marriage for women and her husband in both groups

\begin{tabular}{|c|c|c|c|c|c|}
\hline Case/control & & Mean & Standard deviation & $t$ & $p$ \\
\hline Age of wife & Control (150) Case (134) & 47.173348 .6418 & 7.984675 .46404 & -1.78 & 0.07 \\
\hline Age of husband & Control (150) Case (134) & 53.926754 .7090 & 8.421055 .59380 & -0.911 & 0.363 \\
\hline IQ husband & Control (150) Case (134) & 87.600087 .4552 & 4.733155 .19343 & 0.246 & 0.806 \\
\hline IQ wife & Conrol (150) Case (134) & 87.993387 .6866 & 4.672494 .49631 & 0.562 & 0.574 \\
\hline Duration of marriage & Control (150) Case (134) & 3.20673 .3731 & 1.011991 .10141 & -1.327 & 0.185 \\
\hline
\end{tabular}

Data presented as mean (SD), $p<0.05$ is considered significant IQ intelligent quotient

examinations. Other investigations are semen analysis, hysterosalpingogram, mid-luteal progesterone, and other tests according to each case were done.

Patients were divided into four social classes according to the Egyptian social class classification [17]. Intelligent quotient (IQ) was assessed using Wechsler Adult Intelligence Scale-Revised (WAIS-R) [18], anxiety by Arabic version Hamilton Anxiety Scale [19, 20], depression using the Arabic Form of Hamilton Depression scales [21], self-esteem using the Arabic translation of Rosenberg Self Esteem Scale [22, 23], and Arabic version of Self-esteem and Relationship Questionnaire (SEAR).

The exclusion criteria included the following: learning disability, IQ below 70 using the Arabic version of Wechsler Adult Intelligence Scale-Revised (WAIS-R), any psychiatric disorder proceeding marriage, organic or medical illness that could lead to psychiatric disorders, chronic illness, thyroid disorders, congenital disfigurement, and pituitary disorders that could affect patient self-esteem. Clinically language or hearing disability would interfere with the patient's ability to understand or complete the instruments used in the study.

This study was approved by the Mansoura Faculty of medicine, ethical committee, and Institutional Research Board (IRB) (R.18.10.313) and then it has been performed in accordance with the ethical standards laid down in the 1964 Declaration of Helsinki. Written informed consent was obtained from all participants before inclusion in the study.

\section{Statistical analysis}

Parametric data were summarized as means and standard deviations. Chi-square and $t$ test were used to measure associations found in different non-parametric data and parametric data respectively. The results were computed using the SPSS version 20 program.

\section{Results}

Tables 1 and 2 show no statistically significant difference between infertile and fertile women with regard to women's residence, social standard, religion, type of marriage, age, and intelligence. There was no statistically significant difference between husbands of the two groups of women in terms of age and intelligence. There was also no statistically significant difference between those groups of infertile and fertile women with regard to the duration of the marriage.

Tables 3 and 4 show the prevalence of depression and anxiety in both groups, the scores of the Beck Depression Inventory (BDI), and the Hamilton-A HAM-A in both groups. Women with primary infertility showed a statistically significant higher prevalence of depression and anxiety than fertile women. Also, the scores on the anxiety and depression scales were significantly higher in women with primary infertility than women with children.

Table 5 shows that the women with primary infertility showed lower general self-esteem, sexual satisfaction, sexual relationship, and sexual self-esteem than women

Table 3 Prevalence of depression and anxiety in both groups

\begin{tabular}{|c|c|c|c|c|c|c|}
\hline & & \multicolumn{2}{|l|}{ Case/control } & \multirow[b]{2}{*}{ Chi-square } & \multirow[b]{2}{*}{$p$} & \multirow[t]{2}{*}{ Total } \\
\hline & & Control & Case & & & \\
\hline \multirow[t]{2}{*}{ Depression of wife } & No & $150(100 \%)$ & $52(38.8 \%)$ & 129.05 & 0.000 & $202(71.1 \%)$ \\
\hline & Yes & $0(0.0 \%)$ & $82(61.2 \%)$ & & & $82(28.9 \%)$ \\
\hline \multirow[t]{3}{*}{ Anxiety of wife } & No & $136(90.7 \%)$ & $23(17.2 \%)$ & 155.17 & 0.000 & $159(56.0 \%)$ \\
\hline & Yes & $14(9.3 \%)$ & $111(82.8 \%)$ & & & $125(44.0 \%)$ \\
\hline & Total count percentage & $150(100 \%)$ & $134(100 \%)$ & & & $284(100 \%)$ \\
\hline
\end{tabular}

Data presented as chi-square, $p<0.05$ is considered significant 
Table 4 Scores of BDI and HAM-A in both groups

\begin{tabular}{|c|c|c|c|c|c|}
\hline Case/control & & Mean & Standard deviation & $t$ & $p$ \\
\hline BDI wife & Control (150) Case (134) & 4.853322 .8806 & 2.1343716 .67335 & -13.125 & 0.000 \\
\hline HAM wife & Control (150) Case (134) & 5.860022 .5224 & 4.3226110 .58280 & -17.70 & 0.000 \\
\hline
\end{tabular}

Data presented as mean (SD), $p<0.05$ is considered significant

$B D I$ Beck Depression Inventory, HAM-A Hamilton-A

with children, and the difference was statistically significant.

\section{Discussion}

In the Egyptian culture, infertility is a very stigmatizing problem for both men and women. Failure to have children could lead to many problems extended to complete destruction of a stable family by divorce. To document this problem and to assess the psychological effect that affects the women who bear the most of inferiority feeling, we did this study.

The present study shows that there was no statistically significant difference between women with infertility and with children in residence, social standard and religion, type of marriage, age, and intelligence. Also, husbands of these women were of no statistically significant difference in age and intelligence. Moreover, there was no statistically significant difference between women with infertility and without infertility in the duration of the marriage.

Women with primary infertility show a higher prevalence of depression and anxiety with a highly statistically significant difference than women without infertility. This result could be explained by the fact that women who could not have children have feelings of inferiority and feeling that they are not complete women. Moreover, many of these women feel frustration with anxious feeling mixed with helplessness. They suppress these bitter feelings and cannot express their sadness to anybody. Suppression of these bad feelings in these women leads them to feel anxious and depressed. The result of this study is in harmony of a previous study showing that depression is a common disorder in infertile women [24, 25] and anxiety [26].

The present study found that women with primary infertility showed lower general self-esteem, sexual satisfaction, sexual relationship, and sexual self-esteem than women with children with a statistically significant difference. This could be explained by the fact that in Egypt and most of the Arab countries, women must have given birth and those who could not have children are incomplete women. In many cases, the husband of an infertile woman has to marry second women to have children although he may love his first wife. The family of the husband may do marked press on the husband to marry other woman and if the infertile woman (first wife) refuses the second marriage, the husband has to divorce her. All these situations associated with infertility state put the infertile women under severe stress making them feel low self-esteem in general which suggests that this trouble is mostly association, not a causality relationship. Moreover, many women in Egyptian and Arabic countries feel that sex is useless if they could not have children and make them less interested in sex, less satisfaction in sex, and negative sexual confidence. This again suggests that this problem is mostly association and not causality relationship. This result is in harmony with previous studies found a loss of self-esteem in infertile women [27]. Another study by Wischmann and his colleague (2014) found that women with infertility have clear evidence of a loss of spontaneous sexuality and a negative impact on women's sexual self-esteem [28].

\section{Conclusion}

This study confirms that women with primary infertility are under severe stress in Egyptian culture making them more vulnerable to depression and anxiety. Moreover, they have low self-esteem and unsatisfactory sexual life. All of these effects can add to the infertility problem and make it more difficult to be solved. More attention should be paid to these women to support and help to avoid psychological stress and its consequence.

Table 5 Scores of Rosenberg self-esteem and Self-esteem and Relationship Questionnaire in both groups

\begin{tabular}{|c|c|c|c|c|c|}
\hline Case/control & & Mean & Standard deviation & $t$ & $p$ \\
\hline Rosenberg self-esteem of wife & Control (150) Case (134) & 19.55339 .3134 & 3.382826 .12700 & 17.676 & 0.000 \\
\hline Sexual relation satisfaction & Control (150) Case (134) & 57.953344 .7910 & 13.2990113 .78791 & 8.183 & 0.000 \\
\hline Sexual self-esteem & Control (150) Case (134) & 56.020042 .0000 & 11.5621914 .43836 & 9.074 & 0.000 \\
\hline Overall relationship & Control (150) Case (134) & 56.620039 .2313 & 15.0897415 .31028 & 9.628 & 0.000 \\
\hline SEAR total score & Control (150) Case (134) & 56.864444 .0249 & 11.5204412 .36331 & 9.058 & 0.000 \\
\hline
\end{tabular}

Data presented as mean (SD), $p<0.05$ is considered significant

SEAR self-esteem and relationship 


\section{Abbreviations}

BDI: Beck Depression Inventory; HAM-A: Hamilton-A; IQ: Intelligent quotient; IRB: Institutional Research Board; MINI: Mini-International Neuropsychiatric Interview; SEAR: Self-esteem and Relationship Questionnaire; WAISR: Wechsler Adult Intelligence Scale-Revised; WHO: World Health Organization

\section{Acknowledgements}

The authors would like to express their gratitude to all women who participated in the study as well as workers and nurses in Obstetrics and Gynecology department.

Ethics approval and consent to participate

This study was approved by the Mansoura Faculty of medicine, ethical committee, and Institutional Research Board (IRB) (R.18.10.313) and then it has been performed in accordance with the ethical standards laid down in the 1964 Declaration of Helsinki. Written informed consent was obtained from all participants before inclusion in the study.

\section{Authors' contributions}

AZ contributed to the study design, wrote the protocol, obtained the ethical approval and consents, data collection, and writing of the paper. ME contributed to conceptualize the idea, analyze the data, and writing of the paper. Both authors read and approved the final manuscript.

\section{Funding}

There were no sources of funding, direct or indirect, and any connection with any of the researchers with pharmaceutical or organizations. Moreover, no contractual constraints on publishing imposed by the funder.

\section{Availability of data and materials}

The datasets used and/or analyzed during the current study are available from the author, upon acceptance by Mansoura University, on reasonable request.

\section{Consent for publication}

Not applicable.

\section{Competing interests}

The authors declare that they have no competing interests.

\section{Author details}

'Gynecological and Obstetric Department, Mansoura Faculty of Medicine, Mansoura University, Mansoura, Egypt. ${ }^{2}$ Psychiatric Department, Mansoura Faculty of Medicine, Mansoura University, Mansoura, Egypt.

Received: 6 November 2019 Accepted: 26 February 2020 Published online: 05 March 2020

\section{References}

1. Abdel-Azim S (2013) Psychosocial and sexual aspects of female circumcision. Afr J Urol 19:141-14221

2. WHO "infertility". WHO. int. 2013-03-19. Retrieved 2013-065.

3. Cousineau T M, Domar A D. Psychological impact of infertility. Best Pract Res Clin Obstet Gynaecol. 2007;21:293-308. [PubMed: 17241818]

4. El Kissi Y, Romdhane AB, Hidar S et al (2013) General psychopathology, anxiety, depression and self-esteem in couples undergoing infertility treatment: a comparative study between men and women. Europ J Obstet Gynecol Reprod Biol. 167:185-189

5. Wischmann T H. Sexual disorders in infertile couples. J Sex Med. 2010; 7: 1868-1876 [PubMed: 20214712].

6. Millheiser L S, Helmer A E, Quintero R B. et al. Is infertility a risk factor for female sexual dysfunction? A case-control study. Fertil Steril. 2010;94:20222025. [PubMed: 20206929]

7. Wischmann T (2013) Sexual disorders in infertile couples: an update. Curr Opinion Obstet Gynecol. 25:220-222

8. Ferraresi $S R$, Lara L A, de Sa M F. et al. Current research on how infertility affects the sexuality of men and women. Recent Pat Endocr Metab Immune Drug Discov. 2013;7:198-202. [PubMed: 23829396]

9. Monga M, Alexandrescu B, Katz S E. et al. Impact of infertility on quality of life, marital adjustment, and sexual function. Urology. 2004;63:126-130. [PubMed: 14751363]
10. Mojarrad kahani AH, Ghanavi S (2012) The efficacy of effective communication skills training on the self-esteem of girls with physical mobility disability. J Res Rehabil Sci 1:263-271

11. World Health Organization (2010) Developing sexual health programmes: a framework for action. WHO, Geneva. Google Scholar

12. Nolen-Hoeksema S (2014) Abnormal psychology. 2 Penn Plaza, New York, NY 10121: McGraw-Hill, pp 366-367. 978-1-259-06072-4

13. van Andel, Tinde, Hugo de Boer, and Alexandra Towns. "Gynaecological, andrological and urological problems: an ethnopharmacological perspective." Ethnopharmacology (2015): 199.

14. Tao P, Coates R, Maycock B. The impact of infertility on sexuality: a literature review. Australasian Med J. 2011:4:620-627. [PMCID: PMC3562919]

15. Sadek A. 2000. Mini international neuropsychiatric interview (MINI): the Arabic translation Volume 2. Psychiatry Update, Institute of Psychiatry, 23-31.

16. American Psychiatric association (2013) Diagnostic and statistic manual of mental disorders, 5th edition. American Psychiatric association, Washington, p DC7

17. El Gilany A, El Wehady A, ElWasify M (2012) Updating and validation of the socioeconomic status scale for health research in Egypt. Estern MediterraneanHealth J 8(9):962-968

18. Melikeh LK, Ismail ME (1987) Wechsler preview adult intelligence scale. Arabic version, Cairo, Elnahda Elmasria

19. Hamilton M (1976) In: Guy W (ed) "Hamilton Anxiety Scale", ECDEU assessment manual for psychopharmacology. Department of Health, Education, and Welfare, Rockville, MD: U.S, pp 193-1988

20. Fatim L (1992) Hamilton Anxiety Scale (Arabic Version). Anglo Egyptian Press, Cairo

21. Hamilton M (1960) A rating scale for depression. J Neurol Neurosurg Psychiat. 23:56-61

22. Rosenberg M (1965) Society and the adolescent self-image. Princeton, NJ: Princeton University Press

23. Schmitt DP, Allik J (2005) Simultaneous administration of the Rosenberg self-esteem scale in 53 nations: exploring the universal and culture-specific features of global self-esteem. J Personal Soc Psychol 89:623-642

24. Herbert DL, Lucke JC, Dobson AJ (2010) Depression: an emotional obstacle to seeking medical advice for infertility. Fertil Steril. 94(5):1817-1821

25. Qi XJ, Wei LN, Duan YY, Wang CL, LV YP (2008) A survey of anxiety and depression in infertile women. Matern. Child Health Care China. 23(2):228230 (in Chinese)

26. Albayrak E, Gunay O (2007) State and trait anxiety levels of childless women in Kayseri, Turkey. Eur J Contracept Reprod Health Care. 12(4):385-390

27. Behboodi-Moghadam Z, Salsali M, Eftekhar-Ardabily H, Vaismoradi M, Ramezanzadeh F (2013) Experiences of infertility through the lens of Iranian infertile women: a qualitative study. Jpn J Nurs Sci. JJNS. 10(1):41-46

28. Wischmann T, Schilling K, Toth B, Rösner S, Strowitzki T, Wohlfarth K, Kentenich H (2014) Sexuality, self-esteem and partnership quality in infertile women and men. Geburtshilfe Frauenheilkd. 74(8):759-763

\section{Publisher's Note}

Springer Nature remains neutral with regard to jurisdictional claims in published maps and institutional affiliations.

\section{Submit your manuscript to a SpringerOpen ${ }^{\circ}$ journal and benefit from:}

- Convenient online submission

- Rigorous peer review

- Open access: articles freely available online

- High visibility within the field

- Retaining the copyright to your article

Submit your next manuscript at $>$ springeropen.com 